Road noise causes earlier predator detection and flight response in a freeranging mammal

Shannon, G.W.; Crooks, K.R.; Wittemyer, G.; Fristrup, K.M.; Angeloni, L.M.

\title{
Behavioral Ecology
}

DOI:

10.1093/beheco/arw058

Published: 07/04/2016

Peer reviewed version

Cyswllt i'r cyhoeddiad / Link to publication

Dyfyniad o'r fersiwn a gyhoeddwyd / Citation for published version (APA):

Shannon, G. W., Crooks, K. R., Wittemyer, G., Fristrup, K. M., \& Angeloni, L. M. (2016). Road noise causes earlier predator detection and flight response in a free-ranging mammal. Behavioral Ecology, 27(5), 1370-1375. https://doi.org/10.1093/beheco/arw058

\section{Hawliau Cyffredinol / General rights}

Copyright and moral rights for the publications made accessible in the public portal are retained by the authors and/or other copyright owners and it is a condition of accessing publications that users recognise and abide by the legal requirements associated with these rights.

- Users may download and print one copy of any publication from the public portal for the purpose of private study or research.

- You may not further distribute the material or use it for any profit-making activity or commercial gain

- You may freely distribute the URL identifying the publication in the public portal ?

Take down policy

This is a pre-copyedited, author-produced PDF of an article accepted for publication in Behavorial Ecology following peer review. The version of record is available online at:

https://beheco.oxfordjournals.org/content/early/2016/04/07/beheco.arw058.full

Take down policy

If you believe that this document breaches copyright please contact us providing details, and we will remove access to the work immediately and investigate your claim. 


\section{Road noise causes earlier predator detection and flight response in a free-ranging mammal}

3 Graeme Shannon ${ }^{1,2}$, Kevin R. Crooks ${ }^{2}$, George Wittemyer ${ }^{2}$, Kurt M. Fristrup $^{4}$, Lisa M. Angeloni ${ }^{3}$

$5 \quad{ }^{1}$ School of Biological Sciences, Bangor University, Bangor, United Kingdom

$7 \quad{ }^{2}$ Department of Fish, Wildlife, and Conservation Biology, Colorado State University, Fort

8 Collins, Colorado, United States of America

9

$10{ }^{3}$ Department of Biology, Colorado State University, Fort Collins, Colorado, United States of

11 America

12

$13{ }^{4}$ National Park Service, Natural Sounds and Night Skies Division, Fort Collins, CO 80525, USA

15 Correspondence email:

16 g.shannon@bangor.ac.uk

23 Increasing scientific evidence shows that anthropogenic noise can impact behavioral,

24 demographic and community-level processes across a range of taxa - presenting a serious 
25 conservation challenge. Given the direct link between antipredator behavior and fitness, it is

26 important to explore the impacts of noise on vigilance and flight. To do this, we conducted

27 playback experiments to to test whether noise distracts black-tailed prairie dogs from attending to

28 an approaching predator or whether increased noise exposure led to heightened vigilance and

29 responsiveness. Contrary to the 'distracted prey hypothesis', prairie dogs responded at greater

30 distances to the approaching human "predator" and took flight more rapidly in noise than during

31 the quieter control. Greater vigilance is likely to be a function of increased perceived threat as

32 opposed to distraction, enabling the prairie dogs to evade predators sooner. However, there are

33 energetic and potential fitness costs associated with heightened vigilance and flight, including the

34 loss of foraging opportunities. Interestingly the reactiveness of the prairie dogs to the

35 approaching observer increased over the course of the study, but there was no apparent change in

36 their responses to other humans using the natural area. This may reflect their impressive cognitive

37 abilities that enable discrimination between different predators - even human observers. Our

38 findings emphasize that the complex biological responses to anthropogenic noise are dependent

39 upon the biology of the species as well as the acoustic characteristics of the noise source.

41 Key words: anthropogenic disturbance, vigilance, predation, playback, environmental change

\section{INTRODUCTION}

44 Over the past decade, the effects of rising global anthropogenic noise levels on wildlife have

45 received increasing attention from the scientific community (Shannon et al. 2016). Research has

46 demonstrated that noise affects a range of species across the major taxonomic groups in both

47 terrestrial and aquatic environments. The responses range from altered behavior and physiology 
48 of the individual to effects at the population and community level mediated by changes in

49 densities and abundance (Barber et al. 2010; Francis and Barber 2013; Shannon et al. 2016). This

50 presents a pressing challenge for biodiversity conservation (McGregor et al. 2013), particularly

51 given that increasing noise levels are so closely tied to human population growth and

52 development.

53 Evidence concerning the impacts of anthropogenic noise is mounting, with a large

54 number of studies demonstrating impacts of noise on acoustic communication, physiology and

55 movement (particularly in birds and marine mammals; Shannon et al. 2016). Noise may also have

56 important effects on predator-prey interactions. In addition to removing prey animals from the

57 population, predators can indirectly alter behavior and reproductive success as a function of

58 perceived risk (Creel et al. 2007; Zanette et al. 2011). Antipredator behavior is therefore directly

59 linked to fitness and provides a useful metric in terms of the costs associated with noise exposure.

60 Indeed, a significant challenge of noise research has been to translate the short-term behavioral

61 responses into population-level effects, particularly as animals may exhibit behavioral flexibility

62 (e.g. foraging, vocal communication) to compensate for noise exposure. However, if predator

63 detection is compromised, this will directly impact the survival probability of the animals

64 concerned (Simpson et al. 2016).

65 Noise can affect the behavior of prey species in three distinct ways, including distracting

66 animals from detecting an approaching predator (Chan and Blumstein 2011; Blumstein 2013),

67 reducing auditory surveillance by masking the sounds of an approaching predator (Barber et al.

68 2010), or by directly being perceived as a threat (Quinn et al., 2006; Meillere, Brischoux \&

69 Angelier, 2015). The distracted prey hypothesis is perhaps the least explored possibility, though

70 there is some evidence for noise-induced distraction in crustaceans ( Chan et al. 2010a,b; Wale et

71 al. 2013) and fish (Simpson et al. 2015), but see (Voellmy et al. 2014). The hypothesis is based 
72 on the finite attention and information processing capability of an animal. Anthropogenic noise

73 generates an extra peripheral stimulus that can potentially distract the animal from attending to

74 crucial cues in the environment. This effect was clearly demonstrated in wild Caribbean hermit

75 crabs (Coenobita clypeatus), with a simulated predator able to approach closer in noise before the

76 crabs took evasive action (Chan et al. 2010a). Despite these interesting findings, there has been

77 only limited exploration of the distracted prey hypothesis outside of the lab.

78 Our recent research demonstrated that traffic noise altered the aboveground activity of

79 black-tailed prairie dogs (Cynomys ludovicianus; hereon referred to as prairie dogs), which

80 included an increase in their alert behavior (Shannon et al. 2014), concurring with research on

81 Californian ground squirrels (Spermophilus beecheyi) (Rabin et al. 2006). We wanted to now

82 explicitly test whether noise affects the ability of these highly social animals to detect and take

83 flight from an approaching predator. If prairie dogs behave according to the distracted prey

84 hypothesis (Chan et al. 2010, a,b), we predicted that exposure to noise would distract the finite

85 attention of the prairie dogs, delaying the detection of and flight from an approaching predator,

86 relative to a control period without noise. Alternatively, heightened predator detection could be

87 driven by the increased perceived threat associated with noise (risk disturbance hypothesis: Frid

$88 \&$ Dill, 2002), or indirectly by noise masking the transmission of conspecific alarm calls and/or

89 auditory predator cues (Barber et al. 2010). Under these conditions perceived risk would likely be

90 elevated and increased investment in visual scanning of their surroundings could allow earlier

91 detection and flight from an approaching predator (flush early and avoid the rush hypothesis:

92 Blumstein 2010).

\section{METHODS}

94 Study Site 
95 The research was conducted in the Pineridge Natural Area (250 hectares), located on the western

96 boundary of Fort Collins, Colorado. The predominant habitat is shortgrass prairie, which is home

97 to a contiguous population of prairie dogs that extends $2.5 \mathrm{~km}$ from North to South and varies in

98 width between 100-350m from East to West. The population was divided into three discrete

99 study colonies (East, West and South) that were separated by at least 50m. Pineridge has a well-

100 developed trail network that is used by walkers, runners and cyclists. The prairie dogs are

101 therefore accustomed to human activity. However, with only a small county road on the

102 northwest boundary, road noise exposure is minimal. Detailed weather data were available from a

103 nearby weather station at Colorado State University.

105 Experimental approach

10662 experiments (31 noise exposures and 31 controls) were conducted across the three study

107 colonies from 8 October - 8 November 2014, with each colony only sampled once per week (4-7

108 experiments per sampling period). The observer (GS) stood on a walking trail near colony and

109 randomly selected an individual prairie dog that was engaged in foraging and not vigilant or

110 paying attention to the observer. The colonies were comparatively large and continuous in extent,

111 so the number of animals within a radius of $10 \mathrm{~m}$ of the focal individual were counted (mean \pm s.e

$112=2.3 \pm 0.2$ individuals). A remote-controlled speaker was placed directly in line with the animal

113 perpendicular to the walking trail. Prior to the start of the experiment, the observer then moved

$11430 \mathrm{~m}$ further along the trail so that the 'predator' approach would be at an angle of approximately

$11530-45^{\circ}$ relative to the speaker (see Figure 1). The distance to the prairie dog was measured using

116 a laser rangefinder (start distance, 35-65m). Once it was confirmed that the target prairie dog

117 remained relaxed and there was no alarm calling or agitation from animals in the immediate 
118 vicinity, the observer moved toward the target animal at a consistent speed of $0.5 \mathrm{~m} / \mathrm{s}$ (following

119 the protocol in Blumstein et al. 2004). The speed was standardized using pre-experimental

120 training to ensure that a test 'walk' of $20 \mathrm{~m}$ on the day of each experiment fell within $95 \%$

121 accuracy (i.e. 38-42 seconds). A first beanbag was dropped when the prairie dog became alert to

122 the presence of the 'predator' and a second was dropped when the prairie dog took flight. Flight

123 was defined as movement away from the predator - this was generally in the direction of the

124 nearest burrow. The laser range finder was used to measure the distance from each beanbag to the

125 observer's starting position to determine the alert distance and flight initiation distance.

126 Experiments were alternated between control (no noise) and treatment, which involved

127 the broadcast of road noise from the remote-controlled speaker (62dBA Leq at 10m). The road

128 noise was recorded along Interstate 25, 16km South of Fort Collins (see Shannon et al. 2014 for

129 further details). The playback of road noise was initiated using a remote control 2 minutes before

130 the predator approach was initiated. The ambient sound levels were recorded after each

131 experiment (mean $=33 \mathrm{dBA}$ Leq), while the received noise levels were recorded at the end of the

132 treatment (mean $=43 \mathrm{dBA}$ Leq). Prior to each predator approach, the position of the focal animal

133 was noted so that these recordings could be carried out at that same location after the experiment

134 to determine the specific ambient and received sound levels. All sound level measurements were

135 made using a calibrated sound level meter (Larson-Davis 831).

136

137

138

139 Data analysis 
140 The data were analyzed in a generalized linear mixed model (GLMM) framework using the nlme

141 package in R (R Core Development Team 2012), while Akaike's Information Criterion adjusted

142 for small sample size (AICc) was used for model selection (Burnham and Anderson 2002). It was

143 necessary to use a corrected measure for the flight variable, because the maximum distance that

144 an animal can take flight is constrained by the distance that it becomes alert to an approaching

145 predator, which could potentially bias the analysis. We therefore also calculated a 'corrected

146 flight distance', which was the difference between the alert distance and the flight distance (lower

147 values indicate more rapid flight response).

148 The identity of the colony was included as a random effect due to the repeated sampling

149 design. Eleven candidate models were generated a priori for each response variable (alert

150 distance and corrected flight distance) based on several predictors: exposure (treatment vs.

151 control) to test for behavioral differences with and without road noise; Julian day and decimal

152 time, to determine whether behavioral response changed temporally; ambient sound to explore if

153 background sound levels affect response; distance to the nearest individual to establish if the

154 proximity of conspecifics changes behavior and start distance to account for the variation

155 between experiments (Table S1 - electronic supplementary material). Temperature was initially

156 included in the models as it has been shown to influence prairie dog activity (Shannon et al.

157 2014). However, it was removed from the final analyses due to the strong correlation with Julian

158 day and decimal time. Further exploration of the data also revealed that temperature did not play

159 a role in explaining the alert or flight responses of the prairie dogs. An interaction explored

160 whether behavioral response to noise exposure versus the control changed in relation to the

161 starting position (start distance) of the observer. The AICcmodavg package was used to extract

162 AICc scores and model weights for candidate models of each response variable. Model averaging

163 was conducted on the response specific models accounting for $\geq 0.95$ of the AICc weight to 
164 extract parameter $\beta$-estimates and their $95 \%$ confidence intervals. The effect sizes were assessed

165 by whether the $95 \%$ confidence intervals overlapped zero.

166

\section{RESULTS}

168 The observer was able to approach closer to the target animal during control experiments

169 compared with the noise exposure experiments, with average alert and flight initiation distances

170 of $37 \mathrm{~m}$ and $32 \mathrm{~m}$ respectively during the control experiments, compared to $41 \mathrm{~m}$ and $37 \mathrm{~m}$ for the

171 treatment experiments (Figure 2a). The mean starting distance was the same for both the control

172 and treatment $(47 \mathrm{~m})$, allowing for direct comparison (Figure 2a). Corrected flight distances

173 demonstrated that prairie dogs took flight more rapidly after detecting the approaching predator

174 during noise exposure compared with the quieter control (Figure 2b).

175 Nine models contributed 95\% of the AICc weight for the alert behavior GLMM analysis

176 (Table 1), with the top three models accounting for $54 \%$ of the weight. Model averaging revealed

177 that exposure to traffic noise was a key predictive explanatory variable (Table 2), with alert

178 distances greater during the playbacks of noise. The only other important predictor variable was

179 starting distance with a positive effect indicating that the greater the distance at which the

180 observer initiated the approach, the greater the alert distance.

181 The analysis of the corrected flight data (the distance between the animal becoming alert

182 and taking flight) generated 9 top models, with the top three accounting for $56 \%$ of the AICc

183 weight (Table 1). Exposure was again a key parameter (Table 2), with more rapid flight in the

184 noise treatment than during the control. As with alert behavior, start distance appeared to be

185 positively correlated with corrected flight distance, but the relationship was relatively weak with

186 the $95 \%$ confidence intervals marginally overlapping zero. Julian day was also an important 
187 parameter in the analysis, with a negative relationship indicating that the subjects took flight

188 sooner as the experiments progressed. Indeed, the decline in corrected flight distances across both 189 the control and treatment periods could be predicted with a relatively high degree of precision 190 using the best model (Figure 3).

191

\section{DISCUSSION}

193 Contrary to the distracted prey hypothesis (Chan and Blumstein 2011; Blumstein 2013), prairie 194 dogs became alert and took flight earlier when a simulated predator approached during 195 experimental noise exposure. These results and our previous research (Shannon et al. 2014) 196 suggest that the introduction of a novel acoustical stimulus increases focused vigilance and 197 predator detection, rather than causing distraction, concurring with the risk disturbance 198 hypothesis (Frid and Dill 2002). To our knowledge, this study provides the first detailed test of 199 the distracted prey hypothesis in a mammal - free ranging or otherwise. It also further 200 emphasizes the complex biological responses driven by noise exposure, which are dependent 201 upon the biology of the focal species (e.g. behavioral state, cognition, sociality, trophic level, 202 hearing range, vocal behavior) (Ellison et al., 2012; Francis \& Barber, 2013; Shannon et al., 203 2016). Indeed, a number of crustaceans and fish species have demonstrated marked distraction 204 and impaired antipredator behavior when exposed to anthropogenic noise under both natural and

205 laboratory conditions ( Chan et al. 2010a,b; Wale et al. 2013, Simpson et al. 2015). A recent 206 study on damselfish, which combined field and laboratory experiments demonstrated for the first 207 time that exposure to noise not only changed antipredator behavior, but directly resulted in 208 greater mortality due to increased predation (Simpson et al. 2016). 
Although prairie dogs are still capable of detecting and responding to an approaching

210 predator under noisy conditions, they also demonstrate that greater vigilance causes animals to be

211 more reactive and take flight earlier. These findings fit with the flush early and avoid the rush

212 hypothesis, which predicts that animals will take flight soon after detection of a potential predator

213 so as to limit the attentional costs of continued surveillance (Blumstein 2010; Samia et al. 2013).

214 Nevertheless, such a response - which is likely further exacerbated by the increased perceived

215 risk associated with noise - may result in increased energetic costs associated with flight and lost

216 foraging opportunities (Preisser et al. 2005), particularly when the approaching threat is relatively

217 benign. Our results also concur with a recent study on nesting sparrows, which demonstrated that

218 females exposed to noise flushed from nests sooner than individuals in ambient conditions, which

219 could impact nestling development (Meillere et al. 2015).

Acoustical masking of an approaching predator has been proposed as a mechanism to

221 explain increased vigilance (Barber et al. 2010), and the perception of reduced auditory detection

222 may have increased prairie dog vigilance during our noise treatments. However, acoustic

223 masking did not appear to reduce the actual detection of the "predator" in our study, particularly

224 as approaches were conducted quietly at distances of $\geq 35 \mathrm{~m}$. Indeed, hearing may not play a major

225 role in the detection of natural predators in this open habitat where vision is primarily used to

226 detect stealthy predators (e.g. coyotes, eagles). However, it is also important to consider that

227 acoustical masking may also reduce the signaling distance of conspecific vocalizations (e.g.

228 alarm calls) during exposure to noise, which has been shown to alter behavior and even

229 demography in a range of taxa (Shannon et al. 2016).

230 Over the course of the study, the prairie dogs appeared to become sensitized and more

231 reactive to the approaching predator during both the control and treatment experiments. In fact, in

232 situations where non-target prairie dogs were foraging in close proximity $(<15 \mathrm{~m})$ to the pathway, 
233 the observer found it increasingly challenging to pass by without eliciting vigilance and alarm

234 calls. Interestingly, this reaction appeared to be targeted specifically at the observer, while

235 passing hikers, runners and cyclists were largely ignored. Previous research has demonstrated

236 that prairie dogs can discriminate between different predators and human observers, labelling

237 them with distinct alarm calls (Slobodchikoff et al. 1991; Kiriazis and Slobodchikoff 2006;

238 Slobodchikoff and Placer 2006; Slobodchikoff et al. 2009). Furthermore, prairie dogs exhibited

239 increased reactivity, not habituation, in experiments that involved repeated human intrusion on a

240 colony (Magle et al. 2005). It is also important to reiterate, that despite evidence of overall

241 increased sensitization to the approach of the observer, predator detection and flight was

242 consistently more rapid during noise exposure experiments throughout the study.

243 Longer-term experiments are required to determine whether continued exposure to noise

244 would ultimately result in habituation. It is important to note that just because a species inhabits a

245 noisy area does not mean it has habituated to the disturbance or is immune to its costs (Francis

246 and Barber 2013). Prairie dogs are a prime example of a species found in habitats close to human

247 habitation and infrastructure, but this may be a consequence of rapid human development and the

248 challenge of an entire colony relocating, rather than tolerance of human presence. Indeed, prairie

249 dog populations have declined dramatically over the past 100 years as a result of habitat loss and

250 fragmentation (Miller et al. 1994). The costs of external stressors such as noise may well

251 exacerbate the vulnerability of remaining prairie dog colonies to other heterotypic environmental

252 stressors (e.g. disease, habitat fragmentation, human activity).

253 Our findings demonstrate the ability of prairie dogs to identify the threat of an

254 approaching predator in anthropogenic noise without becoming distracted like other species

255 (Chan et al. 2010a; Wale et al. 2013; Simpson et al. 2015). Nonetheless, greater vigilance and 256 responsiveness due to chronic noise exposure can be costly behaviors that may have potential 
257 energetic and fitness consequences at the population level. Future investigation is required to

258 understand how antipredator behavior is affected by fluctuating sound levels at sites that

259 experience chronic anthropogenic noise exposure (e.g. urban prairie dog populations), as well as

260 contrasting the effects of anthropogenic noise on alert and flight initiation distances with natural

261 sounds (e.g. wind). It would also be interesting to determine if the detection of predator

262 vocalizations and conspecific alarm calls would be masked in the presence of noise, and if so,

263 whether prairie dogs use vocal adjustments (e.g. change in pitch and/or frequency shown by a

264 number of urban bird species: Slabbekoorn 2013) to mitigate potential acoustical masking in

265 noisy areas.

266

267 Acknowledgements

268 The National Park Service Natural Sounds and Night Skies Division funded this research. We

269 would like to thank Jennifer Shanahan and Aran Meyer at Fort Collins Natural Areas for

270 logistical support and permission to conduct the study, Damon Joyce and Chris Garsha for

271 designing and building the remote-triggered speaker, and Line Cordes for statistical advice.

272

273 REFERENCES

274 Barber JR, Crooks KR, Fristrup KM. 2010. The costs of chronic noise exposure for terrestrial 275 organisms. Trends Ecol. Evol. 25:180-189.

276 Blumstein DT. 2010. Flush early and avoid the rush: a general rule of antipredator behavior?

277 Behav. Ecol. 21:440-442.

278 Blumstein DT. 2013. Attention, habituation, and antipredator behaviour: implications for urban

279 birds. Avian urban ecology: Behavioural and physiological adaptations (2014): 41-53. 
Blumstein DT, Runyan A, Seymour M, Nicodemus A, Ozgul A, Ransler F, Im S, Stark T, Zugmeyer C, Daniel JC. 2004. Locomotor ability and wariness in yellow-bellied marmots. Ethology 110:615-634.

283 Burnham K, Anderson D. 2002. Model selection and multimodel inference: a practical 284 information-theoretic approach. Springer Science \& Business Media.

285 Chan AAY-H, Giraldo-Perez P, Smith S, Blumstein DT. 2010. Anthropogenic noise affects risk assessment and attention: the distracted prey hypothesis. Biol. Lett. 6:458-461.

287 Chan AAYH, Blumstein DT. 2011. Attention, noise, and implications for wildlife conservation and management. Appl. Anim. Behav. Sci. 131:1-7.

Chan AAYH, David Stahlman W, Garlick D, Fast CD, Blumstein DT, Blaisdell AP. 2010. Increased amplitude and duration of acoustic stimuli enhance distraction. Anim. Behav.

Creel S, Christianson D, Liley S, Winnie J. 2007. Predation Risk AffectsReproductive Physiology and Demography of Elk. Science. 315:960.

294 Ellison WT, Southall BL, Clark CW, Frankel AS. 2012. A New Context-Based Approach to Assess Marine Mammal Behavioral Responses to Anthropogenic Sounds. Conserv. Biol. 26:21-28.

Francis CD, Barber JR. 2013. A framework for understanding noise impacts on wildlife: an urgent conservation priority. Front. Ecol. Environ. 11:305-313.

Frid A, Dill L. 2002. Human-caused disturbance stimuli as a form of predation risk. Ecol. Soc. 6:11-26.

301 Kiriazis J, Slobodchikoff CN. 2006. Perceptual specificity in the alarm calls of Gunnison's prairie dogs. Behav. Processes 73:29-35.

303 Magle S, Zhu J, Crooks KR. 2005. Behavioral Responses To Repeated Human Intrusion By 
305 Mcgregor PK, Horn AG, Leonard ML, Thomsen F. 2013. Animal Communication and Noise. Brumm H, editor. Berlin, Heidelberg: Springer Berlin Heidelberg (Animal Signals and Communication).

Meillere A, Brischoux F, Angelier F. 2015. Impact of chronic noise exposure on antipredator behavior: an experiment in breeding house sparrows. Behav. Ecol. 26:569-577.

310 Miller B, Ceballos G, Reading R. 1994. The prairie dog and biotic diversity. Conserv. Biol. 8:677-681.

312 Preisser EL, Bolnick DI, Bernard MF. 2005. Scared To Death? The effects of intimidation and consumption in predator-prey interactions. Ecology 86:501-509.

314 Quinn JL, Whittingham MJ, Butler SJ, Cresswell W. 2006. Noise, predation risk compensation 315 and vigilance in the chaffinch Fringilla coelebs. J. Avian Biol. 37:601-608.

316 Rabin L a., Coss RG, Owings DH. 2006. The effects of wind turbines on antipredator behavior in California ground squirrels (Spermophilus beecheyi). Biol. Conserv. 131:410-420.

318 Samia DSM, Nomura F, Blumstein DT. 2013. Do animals generally flush early and avoid the rush? A meta-analysis. Biol. Lett. 9:20130016. modifies behaviour of a keystone species. Anim. Behav. 94:135-141. Nelson MD, White C, Briggs J, et al. (online). A synthesis of two decades of research documenting the effects of noise on wildlife. Biol Rev.

325 Simpson SD, Purser J, Radford AN. 2015. Anthropogenic noise compromises antipredator behaviour in European eels. Glob. Chang. Biol. 21:586-593. 
329 Slabbekoorn H. 2013. Songs of the city: noise-dependent spectral plasticity in the acoustic 330 phenotype of urban birds. Anim. Behav. 85:1089-1099.

331 Slobodchikoff CN, Kiriazis J, Fischer C, Creef E. 1991. Semantic information distinguishing individual predators in the alarm calls of Gunnison's prairie dogs. Anim. Behav. 42:713719.

334 Slobodchikoff CN, Paseka A, Verdolin JL. 2009. Prairie dog alarm calls encode labels about 335 predator colors. Anim. Cogn. 12:435-439.

336 Slobodchikoff CN, Placer J. 2006. Acoustic structures in the alarm calls of Gunnison's prairie dogs. J. Acoust. Soc. Am. 119:3153.

338 Voellmy IK, Purser J, Simpson SD, Radford AN. 2014. Increased Noise Levels Have Different 339 Impacts on the Anti-Predator Behaviour of Two Sympatric Fish Species. PLoS One $340 \quad 9: \mathrm{e} 102946$.

341 Wale MA, Simpson SD, Radford AN. 2013. Noise negatively affects foraging and antipredator 342 behaviour in shore crabs. Anim. Behav. 86:111-118.

343 Zanette LY, White a. F, Allen MC, Clinchy M. 2011. Perceived Predation Risk Reduces the $344 \quad$ Number of Offspring Songbirds Produce per Year. Science. 334:1398-1401. 
346 Table 1. Top models of prairie dog (a) alert distance and (b) corrected flight distance accounting

347 for $\geq 0.95$ of the AICc weight. All models include the identity of the colony as a random effect.

348 Parameters in the interaction terms are also included in the model additively.

349

\begin{tabular}{|c|c|c|c|}
\hline & $\mathrm{K}^{1}$ & $\triangle \mathrm{AICc}$ & AICc weight \\
\hline \multicolumn{4}{|l|}{ a) Alert Distance } \\
\hline Exposure + Start Distance + Julian Day & 6 & 0.00 & 0.22 \\
\hline Exposure + Start Distance & 5 & 0.04 & 0.22 \\
\hline Exposure $*$ Start Distance & 6 & 1.58 & 0.10 \\
\hline Exposure + Start Distance + Nearest Individual & 6 & 1.79 & 0.09 \\
\hline Exposure + Start Distance + Julian Day + Nearest Individual & 7 & 1.85 & 0.09 \\
\hline Exposure + Start Distance + Time & 6 & 2.30 & 0.07 \\
\hline Exposure + Start Distance + Ambient Sound & 6 & 2.48 & 0.06 \\
\hline Exposure + Start Distance + Julian Day + Time & 7 & 2.53 & 0.06 \\
\hline Exposure + Start Distance + Julian Day + Ambient Sound & 7 & 2.53 & 0.06 \\
\hline \multicolumn{4}{|l|}{ b) Flight Distance (corrected) } \\
\hline Exposure + Start Distance + Julian Day & 6 & 0.00 & 0.30 \\
\hline Exposure + Start Distance + Julian Day + Nearest Individual & 7 & 1.45 & 0.14 \\
\hline Exposure + Start Distance + Julian Day + Time & 7 & 1.74 & 0.12 \\
\hline Exposure + Start Distance & 5 & 2.31 & 0.09 \\
\hline Exposure + Start Distance + Julian Day + Ambient Sound & 7 & 2.40 & 0.09 \\
\hline Exposure * Start Distance & 6 & 2.48 & 0.09 \\
\hline Exposure + Start Distance + Nearest Individual & 6 & 3.69 & 0.05 \\
\hline $\begin{array}{l}\text { Exposure }+ \text { Start Distance }+ \text { Julian Day }+ \text { Ambient Sound + } \\
\text { Nearest Individual }\end{array}$ & 8 & 3.70 & 0.05 \\
\hline Exposure + Start Distance + Ambient Sound & 6 & 4.26 & 0.04 \\
\hline
\end{tabular}


353 Table 2. The observed relationship between each response variable and the model-averaged

354 parameters from the top models $(\beta$-estimate $\pm 95 \% \mathrm{CI})$. Bold text denotes $\beta$-estimates with $95 \%$

355 CI that do not overlap zero.

356

\begin{tabular}{llcc}
\hline & Parameter & $\boldsymbol{\beta}$ Estimate & $\mathbf{( 9 5 \% ~ C I ) ~}$ \\
\hline Alert Distance & Exposure & $\mathbf{3 . 9 5}$ & $\mathbf{( 2 . 1 3 / 5 . 7 7 )}$ \\
& Julian day & 0.08 & $(-0.02 / 0.18)$ \\
& Time & -0.06 & $(-0.79 / 0.67)$ \\
& Ambient sound level & 0.00 & $(-0.34 / 0.34)$ \\
& Nearest Individual & -0.10 & $(-0.32 / 0.13)$ \\
Flight Distance & Exposure & $\mathbf{0 . 8 3}$ & $\mathbf{( 0 . 7 2} / \mathbf{0 . 9 4 )}$ \\
& Start Distance & 0.11 & $(-0.11 / 0.32)$ \\
& Exposure * Start Distance & & \\
& Julian day & $\mathbf{- 1 . 7 2}$ & $\mathbf{( - 2 . 9 7 / - 0 . 4 7 )}$ \\
& Time & $\mathbf{- 0 . 0 8}$ & $\mathbf{( - 0 . 1 5 / - 0 . 0 1 )}$ \\
& Ambient sound level & -0.18 & $(-0.70 / 0.33)$ \\
& Nearest Individual & 0.08 & $(-0.16 / 0.30)$ \\
& Start Distance & 0.07 & $(-0.07 / 0.24)$ \\
& Exposure * Start Distance & -0.12 & $(-0.01 / 0.15)$ \\
& &
\end{tabular}

357

358

359

360

361

362

363

364

365 
366 Figure 1. Experimental setup used at the three prairie dog colonies in Pineridge Natural Area, 367 Fort Collins, Colorado.

368

369 Figure 2. Prairie dog responses to predator approach. (a) The mean $( \pm$ SE) observer start distance, 370 and alert and flight initiation distances of the target prairie dog during the road noise treatment 371 and control experiments. (b) The mean $( \pm$ SE) corrected flight distance (distance for the target

372 animal to take flight after becoming alert to the approaching predator) for the road noise 373 treatment and control experiments.

374

375 Figure 3. Corrected flight distances predicted for the entire 31-day study period using the best 376 model. The shaded areas show the $95 \%$ confidence intervals with the darkest shading indicating 377 areas of overlap.

378

379 